\title{
Comentário ao artigo "Sobre as consequências filosóficas do primado da percepçáo em Merleau-Ponty"
}

\author{
Gisele Batista Candido ${ }^{1}$
}

Referência do texto comentado: CAMARGO, Jeovane. Sobre as consequências filosóficas do primado da percepção em Merleau-Ponty. Trans/Form/Açáo: revista de filosofia da Unesp, vol. 43, Número Especial, p. 231-256, 2020.

Conforme Merleau-Ponty, habitamos o mundo antes de pensarmos sobre ele. Em outras palavras, o solo que habitamos é uma verdade prévia à reflexão:

O mundo náo é um objeto do qual possuo comigo a lei de constituição; ele é o meio natural e o campo de todos os meus pensamentos e de todas as minhas percepçóes explícitas. [...] O homem está no mundo e é no mundo que ele se conhece. (MERLEAU-PONTY, 1999, p. 6)

Animado por essa constatação, o filósofo francês se lança ao estudo fenomenológico da percepção, a fim de refletir sobre a estruturação de nosso conhecimento e as condiçóes de nossa existência. Uma vez que cumpre à fenomenologia compreender como estamos no mundo e de que forma ele sempre faz sentido para nós, a percepção será eleita por Merleau-Ponty como um fenômeno privilegiado, pois ela é a experiência corporal primordial, a qual inaugura nossa presença no mundo: “[...] a percepção não é uma ciência do mundo, não é nem mesmo um ato, uma tomada de posição deliberada; ela é o fundo sobre o qual todos os atos se destacam e ela é pressuposta por eles" (MERLEAU-PONTY, 1999, p. 6). Enquanto solo originário de todas as outras experiências, a percepção assume assim um papel central

${ }^{1}$ Docente no Departamento de Fundamentos da Educação/FE - UFRJ, Rio de Janeiro, Rio de Janeiro
- Brasil. (D) https://orcid.org/0000-0001-7182-3192 E-mail: giselebc@gmail.com http://doi.org/10.1590/0101-3173.2020.v43esp.19.p263 
nas reflexôes merleau-pontyanas. Em seu artigo "Sobre as consequências filosóficas do primado da percepção em Merleau-Ponty”, Jeovane Camargo procura analisar os desdobramentos dessa suposição sobre a existência de uma condição primordial, articulando astutamente a primeira e a segunda fase do pensamento merleau-pontyano.

Para tanto, ele partirá de uma autocritica presente no $O$ visivel $e$ o invisivel (1964), em que Merleau-Ponty assume a presença de um lastro de dicotomia na noção de consciência-objeto, em suas obras pregressas: $A$ estrutura do comportamento (1942), O primado da percepção e suas consequências filosóficas (1946), O metafísico no homem (1947) e a Fenomenologia da percepção (1945). Diante dessa constatação do filósofo francês, Camargo formula duas questôes, não apenas relevantes, mas sobretudo nevrálgicas para um estudo profundo e crítico do fenômeno perceptivo na obra de Merleau-Ponty, bem como de suas limitaçóes: uma vez que o filósofo francês reconhece resquícios dualistas em suas obras passadas, os quais, segundo ele, foram responsáveis por "problemas insolúveis", faz-se mister considerar quais são esses problemas e qual a dimensão dessa dicotomia, porquanto a percepção surge como um fenômeno que justamente permitiria ao filósofo se esquivar dos prejuízos dos modelos dicotômicos clássicos.

Assim, Camargo percorre com seu artigo um caminho astucioso, ao considerar um problema assumido posteriormente pelo próprio MerleauPonty, para desenvolver um estudo retrospectivo e atual sobre um fenômeno crucial na obra desse filósofo. Nesse horizonte, o autor do artigo em questão mostrará como a temporalidade, a noção de mundo, a linguagem e a corporalidade estão diretamente envolvidas, não apenas à forma como Merleau-Ponty desenvolve sua noção de percepção, mas também com os problemas insolúveis posteriormente reconhecidos pelo filósofo. Para Camargo, Merleau-Ponty teria recaído em prejuízos análogos aos dos modelos dualistas, ao assumir a existência de uma espécie de primado da percepção, enquanto experiência originária, em oposição às experiências, por assim dizer, derivadas. Tais prejuízos inclusive perdurariam em sua obra mais tardia. Ao trazer à baila essa posição polêmica, o autor ainda recorre pontualmente e pertinentemente a outros autores, como Nietzsche e Alberto Caeiro, de sorte a exemplificar e reforçar suas críticas e sua posição. Por isso, seu artigo apresenta um estudo relevante, contundente e polêmico - no modo como conduz sua crítica e seus paralelos - da obra de Merleau-Ponty. 
Sabemos, no entanto, que existem muitas formas de percorrer uma obra filosófica e que sua interpretação jamais será unívoca. Logo, e porque se trata de um artigo prolífero, fruto de um trabalho cuidadoso, nós nos vemos diante de questôes que podem, com justeza, nortear nossos estudos.

Merleau-Ponty (2000, p. 15) não deixa de reconhecer as dificuldades na formulação de reflexôes que excedem o exercício habitual da linguagem:

Vemos as coisas mesmas, o mundo é aquilo que vemos - fórmulas desse gênero exprimem uma fé comum ao homem natural e ao filósofo desde que abre os olhos, remetem para uma camada profunda de opinióes mudas, implícitas em nossa vida. Essa fé tem isso de estranho: se procurarmos articulá-la numa tese ou num enunciado, se perguntarmos o que é este nós, o que é este ver e o que é esta coisa ou este mundo, penetramos num labirinto de dificuldades e contradiçóes.

Às voltas com o arcabouço terminológico herdado da tradição filosófica, como, por exemplo, as noçóes de sujeito/objeto ou corpo/espírito, MerleauPonty se encontra na dupla dificuldade de falar sobre experiências que evadem os conceitos e as categorias tradicionais da Filosofia, dispondo justamente desses termos, e, ao mesmo tempo, tecer uma crítica ao uso que a tradição fez dessa terminologia. Conforme Barbaras (2011, p. 215),

[...] ele encontra-se numa situação desconfortável uma vez que, longe de poder apoiar-se na linguagem, ele deve, por assim dizer, lutar contra ela o tempo todo, tentar fluidificar a estrutura rígida da linguagem filosófica, criticar sem parar conceitos que, por outro lado, ele náo pode deixar de usar.

Diante dessas colocaçóes, em que medida os percalços merleaupontyanos comprometem os alicerces de sua filosofia? Não seriam eles apenas reflexo das limitações dessa linguagem que Merleau-Ponty herdou da tradição filosófica? Aliás, em que medida é possível fazer essa dissociação entre a forma de expressão e o sentido do que é expresso?

Ao reconhecer que é a cisão entre sujeito e objeto que configura o cerne dos prejuízos empiristas e intelectualistas, Merleau-Ponty enfatizara, em sua Fenomenologia da percepçáo, que ambas as tradiçóes, na tentativa de retomar o evento primordial do conhecimento com o intuito de compreendêlo, arbitrariamente concebiam um corte entre sujeito e objeto. Como consideravam uma experiência já tardia, conquanto a noção de objeto, segundo o filósofo francês, é já uma construção plenamente determinada, 
como esse primeiro contato revelador, tanto empirismo quanto intelectualismo ignoravam a percepção como abertura originária ao mundo e às coisas. Assim, ignoravam, igualmente, sua ambiguidade implícita, a qual impossibilitaria um corte definitivo entre sujeito e objeto. Ambos sofriam do mesmo prejuízo, a falta de uma reflexão radical que nos levasse a compreender os limites da razão na construção de nosso conhecimento. Tomavam, portanto, por um objeto primário um objeto que, na verdade, já era uma construção da razão, ignorando as implicaçôes suscitadas pela percepção.

Com efeito, Merleau-Ponty abre "O Entrelaçamento - O Quiasma", capítulo de seu $O$ visivel e invisivel, insistindo na necessidade de um retorno a uma camada pré-reflexiva da experiência;

Se é verdade que a filosofia, desde que se declara reflexão ou coincidência, prejulga o que encontrará, torna-se-lhe necessário então recomeçar tudo de novo, rejeitar os instrumentos adotados pela reflexão e pela intuição, instalar-se num local em que estas ainda não se distinguem, em experiências que ainda náo foram 'trabalhadas', que nos ofereçam concomitante e confusamente o 'sujeito' e o 'objeto', a existência e a essência, e lhe dão, portanto, os meios de redefini-los”. (MERLEAU-PONTY. 2000, p. 127)

Embora seja possível falar de natureza e cultura, mundo e homem, não parece ser possível dizer definitivamente em que momento começa um ou termina o outro: “[...] nesse circuito não há nenhuma ruptura, impossível dizer que aqui termina a natureza e começa o homem [...]" (MERLEAUPONTY. 2004, p. 44). Enfim, a preocupação de Merleau-Ponty parece ser mais com a cisão arbitrária que com a existência de dois polos.

Camargo insiste em ressaltar, em seu artigo, que Merleau-Ponty ainda recai em prejuízos dicotômicos, sobretudo ao propor um modelo que apela para a noçáo "corpo $e$ mundo". Sabemos, em contrapartida, que é possível compreender os supostos resquícios dicotômicos da obra merleupontyana, assumindo que essas tensóes são polos imbricados e ambíguos (não necessariamente distintos, uma vez que Merleau-Ponty insiste em sublinhar que não sabemos onde um começa e outro acaba). Nesse horizonte, a crítica merleau-pontyana aos modelos dualistas e os prejuízos advindos deles não estariam mais voltados para o corte - arbitrário - entre um polo e outro? Se sim, ainda seria possível dizer que Merleau-Ponty recai nos mesmos prejuízos que os filósofos dualistas? 


\section{REFERÊNCIAS}

BARBARAS, R. Investigaçóes Fenomenológicas - Em direção a uma fenomenologia da vida. Curitiba: Editora UFPR, 2011.

CAMARGO, Jeovane. Sobre as consequências filosóficas do primado da percepção em Merleau-Ponty. Trans/Form/Açáo: revista de filosofia da Unesp, vol. 43, Número Especial, p. 231-256, 2020

MERLEAU-PONTY, M. Fenomenologia da Percepçáo. São Paulo: Martins Fontes, 1999.

MERLEAU-PONTY, M. O olho e o espírito. São Paulo: Cosac e Naify, 2004 MERLEAU-PONTY, M. O Visível e o Invisível. 4ª ed. São Paulo: Editora Perspectiva, 2000. 
CANDIDO, G. B. 